\title{
Correction
}

to the Paper

\section{Relative Viscosity of Suspensions of Rigid Spheres in Newtonian Liquids}

\author{
By Ir. R. Rutgers (Wormerveer, The Netherlands)
}

Rheol. Acta 2, No. 3, 202-210 (1962)

The tables $1 \mathrm{a}$ and $1 \mathrm{~b}$ reproduced within the contribution had been supervised by both, author and executive editor. Nevertheless, after publication there must be stated that, unfortunately, some lines in the table manuscripts had been changed. To enable the readers to an exact evaluation of the table material we now reproduce here the tables again, which have been corrected and completed by the author: 
Table 1 a

Relative Viscosity of Suspensions of Spheres

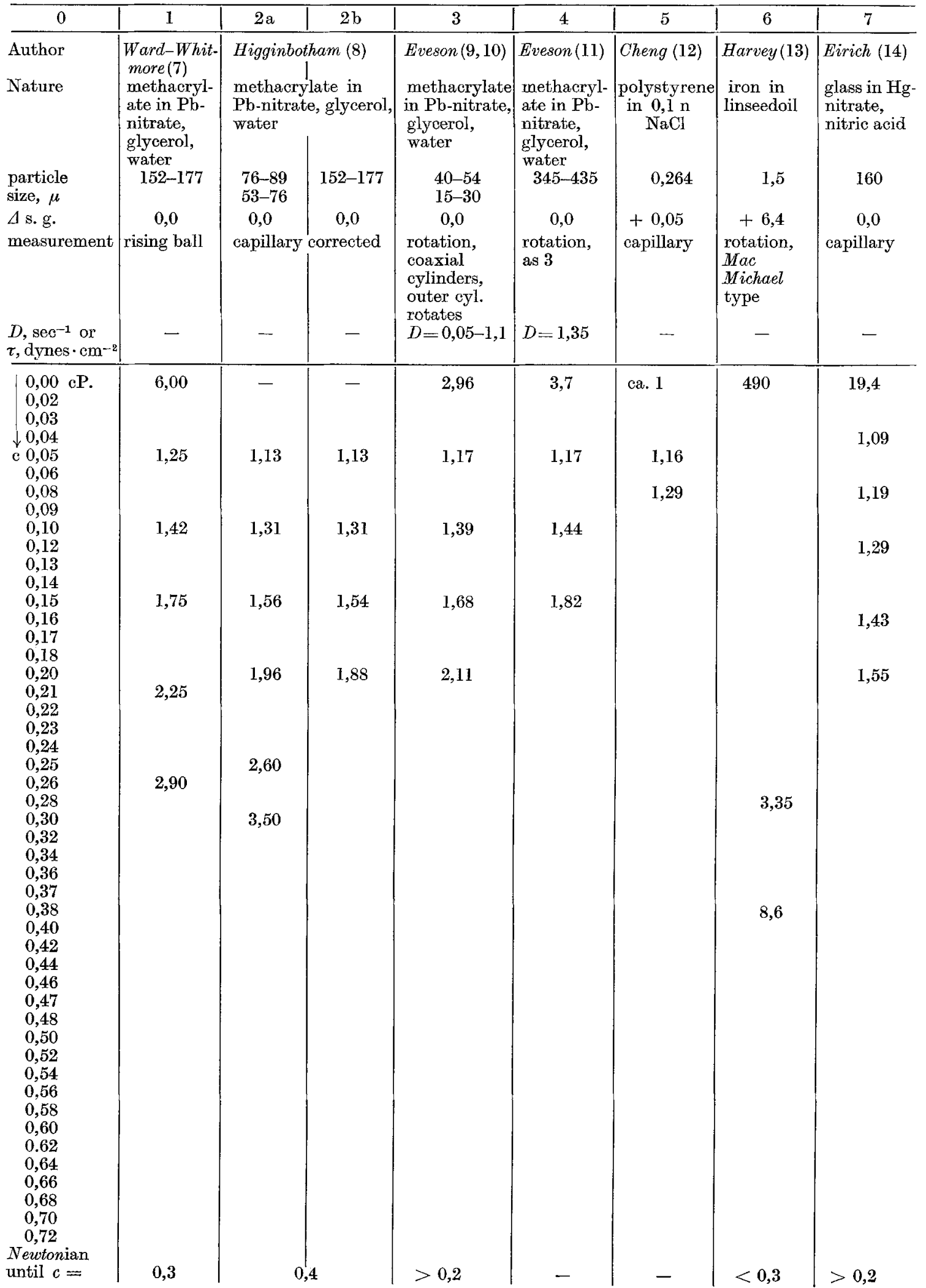


Table $1 a$ (Continuation)

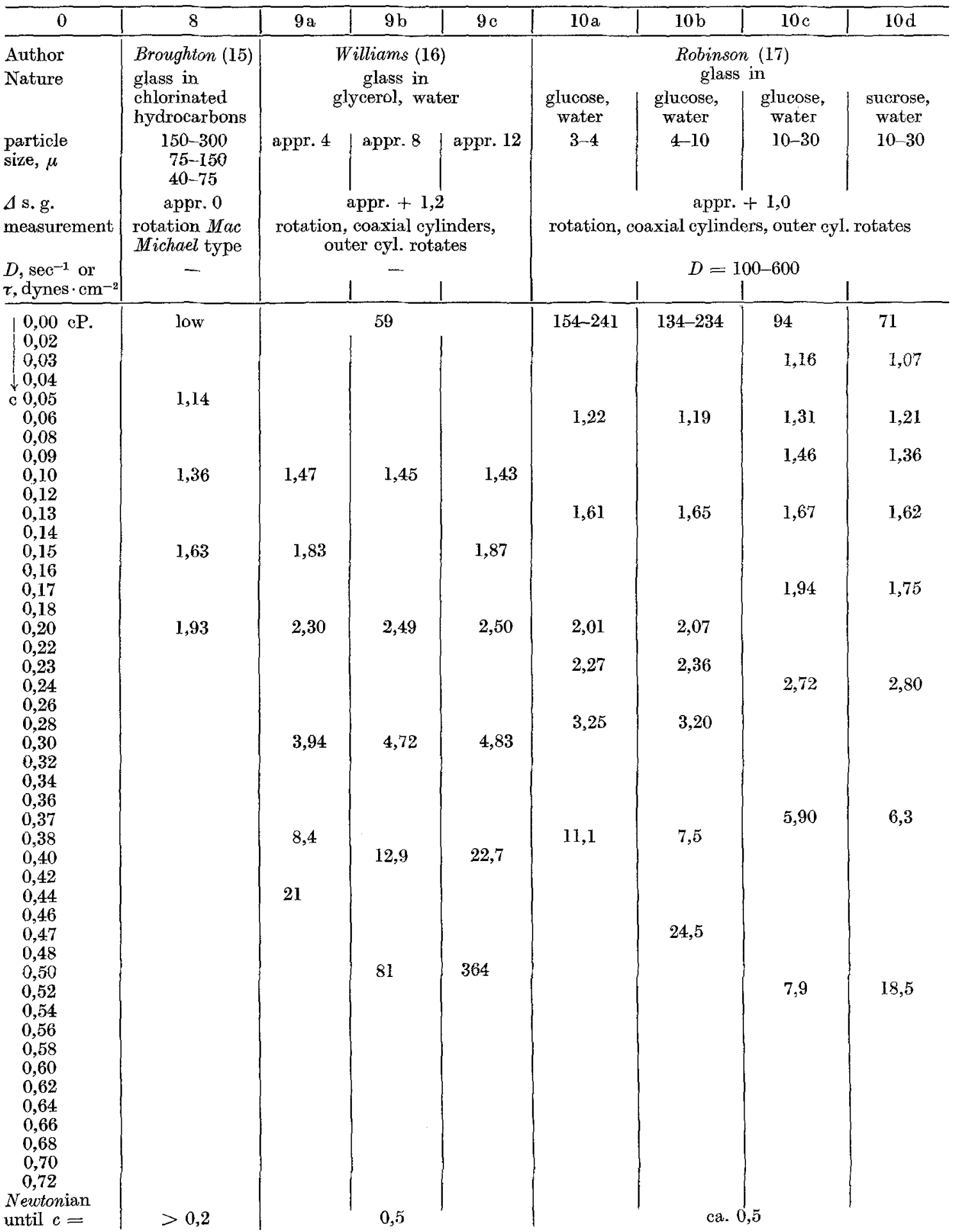


Table $1 b$

Relative Viscosity of Suspensions of Spheres

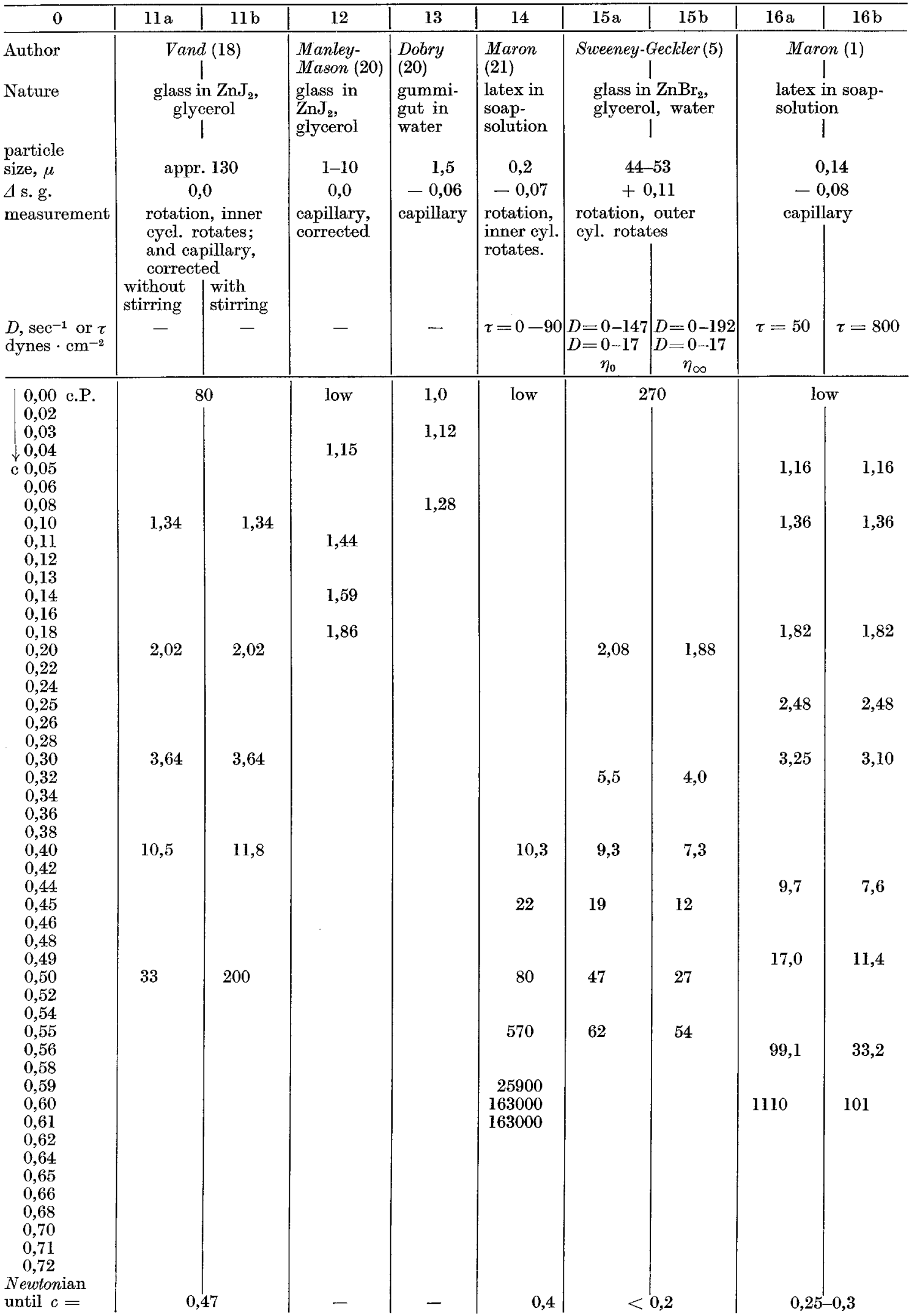


Table $1 b$ (Continuation)

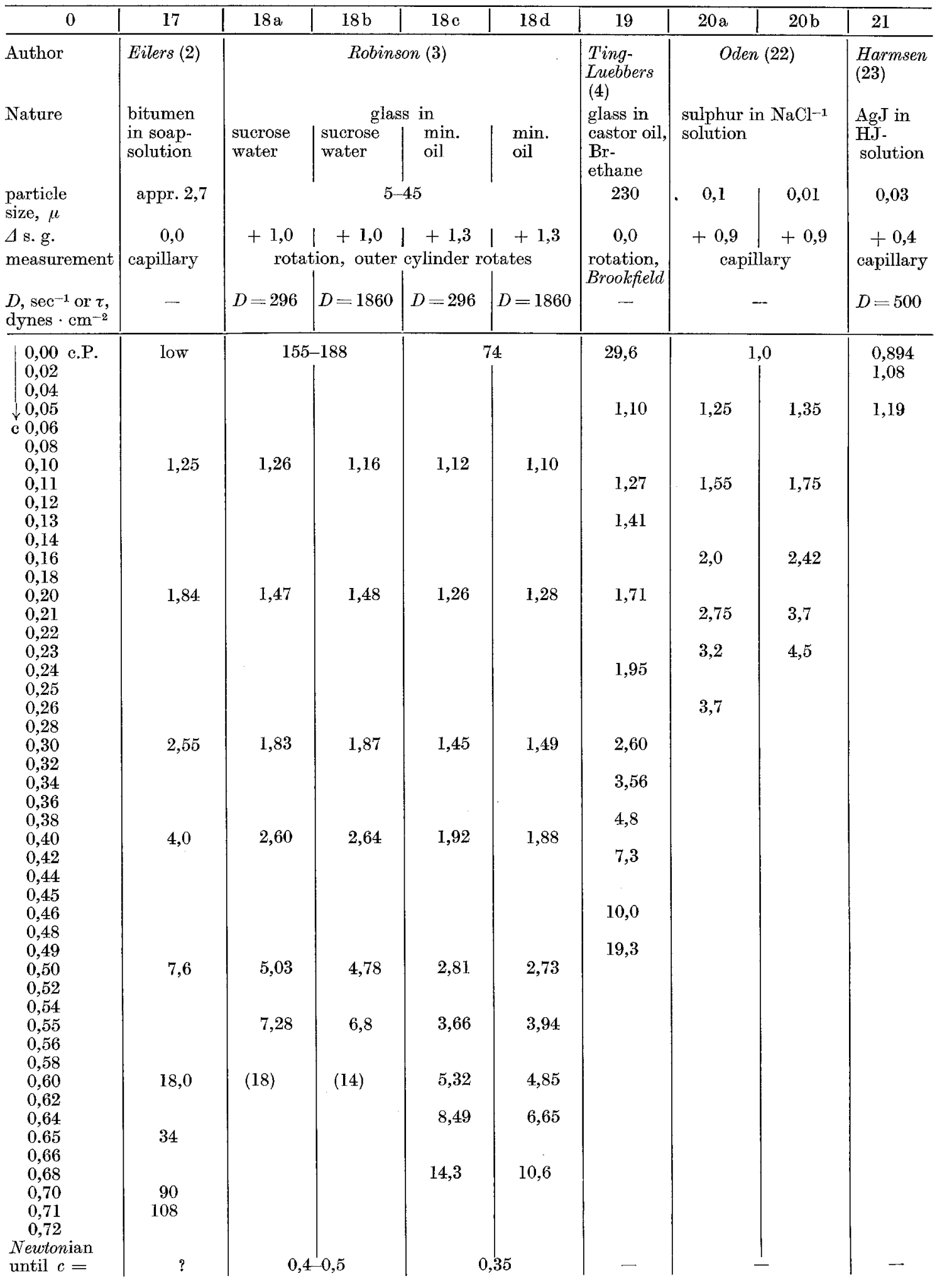

